\title{
Research on Curriculum Design of Deep Learning based on the WeChat
}

\author{
Guixin Zhao \\ School of Information \\ Qilu University of Technology \\ Jinan, China \\ email: guixin79@126.com
}

Keywords: Mobile: WeChat; WeChat Public Platform; Deep Learning

\begin{abstract}
Deep learning is an active, critical way of learning, but also the effective way of meaningful learning. The WeChat is applied to the students in the process of deep learning in the paper. Combined with the distinctive features of the WeChat and several major advantages of the WeChat public platform, the curriculum design of deep learning is studied based on the WeChat under on the guiding principles of the teaching strategies of deep learning based the mobile internet. The curriculum design of deep learning based on the WeChat is comprised of three parts, which are the construction of learning environment, the process of deep learning and the feedback of effect. The flow chart of the whole learning process is drew and the specific implementation of the three parts explained in detail.
\end{abstract}

\section{Introduction}

At present, the teaching activities of many universities in our country are confined to the classroom. The teacher is teaching on the platform and the students are listening in the following lectures, which is the main teaching methods. This process is very difficult to give full play to students' initiative and enthusiasm, adding the purpose of learning being more utilitarian, lacking of learning motivation and single learning method for a lot of students. Students Learn knowledge without depth and are unable to achieve mastery through a comprehensive study of the subject, to learn in order to practice and bring forth the new through the old in order to pass the exam and get a diploma by means of rote learning book knowledge. So many people consider that the practical ability and innovation ability of Chinese college students is relatively weak. If we want to develop students' practical ability and innovation ability in Chinese Universities, we must reform the teaching methods and teaching strategy, encourage students to use less surface learning approach, but to use of the way of deep learning.

With the arrival of the micro era, the brunt is the WeChat. it has more than 600000000 users and 100000000 daily active users. Whether the WeChat public platform or the WeChat circle of friends, the WeChat is speeding to each user's learning life by rocket speed. The WeChat supports to send text, pictures, video and other information. The WeChat is welcome by the majority users because that the WeChat software itself is completely free, while supports the cross platform communication between the various intelligent operating system, and more saves traffic and has other characteristics.

With the improvement of the WeChat function, more and more educational technologists begin to follow with interest in the education effect of the WeChat. First, learners can timely understanding of the concerned latest through focusing on the interest in the WeChat public platform, the circle of friends, message push and other functions in the virtual learning community constructed by the WeChat for learners. Second the user can make use of the brainstorming in order to discuss the problem impetuously through the real-time intercom, mass-chat and other functions. Third the user can also share the wonderful contents been seen with the WeChat friends circle of and let friends of the circle to see through the sharing function of the WeChat. As a kind of social software, the 
WeChat not only provides the space for the learners' personal knowledge management, but also construct a platform for learners to collaborate and share knowledge with each other. The WeChat provides a very effective way of deep learning for college students in the mobile Internet environment.

\section{The factors Promoting the students' deep learning}

Deep learning is a kind of understanding learning. Learners can grasp the theme and the main idea and unearth the implied meaning between the lines through understanding the facts and details of the learning content. From the motivation of learning, deep learning is driven by the intrinsic motivation of learners. The learners have intrinsic interest in the content and learn on their own initiative in order to satisfy their curiosity. From the learning types, deep learning is the senior grade learning based on understanding, delving into and the combination of learning and applying, which requires students to use the senior than memorize mind for learning. Integrated learning requires students to integrate knowledge, skills and capabilities as one of the activities. Reflective learning requires students to explore their own learning experiences in order to better understand how they learn [1].

There are a lot of factors to promote the deep learning, in addition to the students themselves, such as learning objectives, knowledge background, innate ability and other factors, but also the learning situation factors, such as teaching, assessment, curriculum and other factors [2]. The research shows that the situational factors promoting student to learn deeply are: the students' burden avoided heavy burden, the clear target and useful information feedback, to promote the concept of clear, the clear, warm and sympathetic Teaching in order to promote the transformation of ideas for the purpose, freedom of choice for the content and method of learning, the assessment guiding students to focus on the development of their understanding and evaluation of the use of writing rather than a number of options [3].

The study of Marsh and Hulleman et al is that the students' curriculum values have significant influence on their learning style. Curriculum value includes intrinsic value and instrumental value. The performance of the former is that course itself is whether interesting or challenging, and the latter is that the content of the curriculum is whether useful to students' personal life or can improve the students' interest in the subject and students learn the subject content, etc. Surface learning occurs when students think that the curriculum value is low, while deep learning occurs when students think that curriculum value is high and challenging [4]. Offir believes that students would prefer the deep learning if the rigid curriculum structure converts into the flexible one to make the curriculum objectives, learning materials and the methods of assessment to been adjusted and chosen, in order to each appropriate every student's unique needs [5].The study of Thomas and Bain reveals the relationship between the curriculum evaluation and the students' learning style. Students' expectations of learning required by schools and teachers will affect their learning ways. In a way, the assessment provides the course, moreover assessment is one of the things that the students are most concerned about. So the assessment can and should play a central role in the curriculum design. The assessment drives students to participate in activities which strengthen their learning. So carefully designed assessment strategy can ensure that students learn to provide them with the relevant learning resources, to make sure the related learning resources needed by students' learning and ensure the desired learning outcomes produced by their learning activities [6]. In the assessment approach, open writing encourages students to study in deep learning, but a number of questions and short answers to questions lead to students' surface learning.

In a word, the curriculum requirements for deep learning are that the value theory or practice of curriculum, Goal clarity, challenging, integrated, flexible and selective curriculum structure appropriate course burden and paying attention to students' understanding and solving practical problems.

\section{WeChat and WeChat Public Platform}

\section{WeChat}

WeChat is the instant message software launched by Tencent in 2011. It can send text, video, pictures and other forms of media resources through the network, supports voice intercom, 
establishes WeChat group, initiate mass-chat, focuses on topics of interest on the WeChat public platform and shares feelings, pictures, news links etc.in the friends circle. WeChat providing a perfect platform for communication for the user, having the advantage of cross platform, instant messaging, easy operating, strong interaction, has been unanimously welcomed by University students and become an indispensable part of their daily life.

The WeChat as a new form of Internet media has a distinctive feature:

\section{1) The Miniaturization}

The WeChat communication is the micro information dissemination by many small forces. It can be said that the WeChat forms a micro propagation. The basic feature of the micro propagation is that the dissemination contents miniaturize (a picture, a paragraph of text, etc.), the communication medium is a smart phone and other portable devices and propagation occurs in the "micro time" (fragmented, rest of the time).e trivial time when learning resources are developed.

\section{2) The We Media}

The We Media is also known as the citizen media, it is said that the general public and organizations can access the network anytime, anywhere, and connect the global knowledge system.it is a way to share their own facts and news Immediately.

3) The service and the arrival rate

The WeChat based on interpersonal relationships has the e-mail reminders, voice contact and other service functions, but also has a privacy protection features, so that it make users to avoid the harassment of useless information. The WeChat public platform can push the content of the information to the user on the phone directly, and can guarantee effectively the arrival rate of information.

\section{The WeChat public platform}

The WeChat public platform is that it uses the public accounts platform to carry out the media activities, simply to carry out the 0ne to many media activities. The text, audio, video, as well as multi graphic information can be processed, and the function of mass-sending and timely interaction can be achieved in the WeChat public platform. The WeChat public platform comprises of the WeChat subscription number and service number, and can set the key word replies and custom menu. The WeChat subscription number can send pictures, text and video to the users.

The advantages of the WeChat public platform:

4) The high efficiency of interaction

Teachers once send messages to students using the WeChat public platform, and then students can receive messages immediately. The WeChat public platform has a very strong synchronization. Students view the message, reply to the message, and communicate in time with each other. Moreover, when students do not understand the problem needed to be discussed, the teacher can also establish a mass-chat. Those who participate in the study of mass-chat can discuss and communicate with other learners in a timely by voice communication like the face of communication.

5) The richness of message content

The WeChat public platform send a wide variety of messages which are text, pictures, graphics, video and voice, etc.. The Various forms of information on the public platform can stimulate students' interest in learning.

6) The convenient operation

The WeChat public platform is no door shabby restrictions, anyone can apply for a WeChat public platform, of course, teachers no exception. Learners as long as use their own WeChat "sweep" function to sweep the WeChat public platform two-dimensional code provided by teachers, and then they can join the WeChat public platform.

7) The micro of resource material

In the WeChat public platform, the size of the material resources is limited, which is beneficial for the learners to use the micro curriculum resources in the platform for mobile learning in a certain extent. 


\section{The curriculum design of deep learning based on the WeChat}

According to the teaching strategies of deep learning based on the mobile Internet [7], we know that we should follow the following principles in the teaching.

According to the features and the functions of the WeChat and the WeChat public platform, then the main process of the curriculum design of the deep learning based on the WeChat is divided into the following three parts combining with the teaching strategy of deep learning based on mobile Internet (Fig. 1):

\section{Building a learning environment}

Building a learning environment is to construct the deep learning environment based on the WeChat. In this part, there are establishment of the WeChat public platform, students focusing on the WeChat public number and building learning community.

8) the establishment of the WeChat public platform

The first step of the establishment of the WeChat public platform is to apply for the public account. The can be applied for free of charge. The URL is http://mpwexin.qq.com. If you fill in personal information, the real name authentication will be carried out, and then your WeChat public platform account will be opened about 3 to 7 days. Under normal circumstances, a person can only apply for a personal subscription number [8]. First the construction of the WeChat public platform is to upload the curriculum resources including text, pictures and video to the WeChat public platform. The teacher can send the curriculum resources to the students in an appropriate time. Secondly, teachers set the automatic reply function of the WeChat public platform. When the students are in doubt, they can input a key into the WeChat public platform, they can get the answer of their questions automatically from the WeChat public platform.

9) Focusing on the WeChat public number

Focusing on the WeChat public number is that students using the smart mobile terminal scan the two-dimensional code of the course WeChat public platform, add the focus, then subscribe to the course WeChat public platform. Students can receive the texts, pictures and videos mass-sent to the WeChat public platform by the teachers to facilitate the learning course content, and also enter the key words to get the answer of their problem through the automatic reply function of the WeChat public platform[9].

10) The establish of the WeChat group

Teachers establish the WeChat group using their own WeChat number and invite all the students to join in this group to facilitate their brainstorming in order to conducive to the internalization of knowledge.

\section{The process of deep learning}

The process of deep learning includes teachers' sending video, students' learning the curriculum video students, the brainstorming to discuss in the students' WeChat group and searching learning materials using WeChat.

11) Pushing learning video and requirements

According to the learning process, teachers regularly send the course video and the course task to all the students for their own learning. Learning video can be recorded in the classroom, and also be recorded the computer screen when teachers operate the computer.

12) Students see learning video

After the students receive the course video, they can learn the contents of the course according to their own time [9].

13) Students carry out brainstorming in the group

Student have watched the video, let everybody carry out the brainstorming in the WeChat group in order to express their views of new knowledge, and deepen the understanding and the master of new knowledge.

14) Search learning materials on WeChat.

In the process of brainstorming, students may have some other knowledge which is not known. Then they search the learning resources on the network through the search function of the WeChat. 
That can deepen students' understanding of the content of their study, expand the scope of the students' knowledge, and promote the internalization of their learning content.

\section{Effectiveness Evaluation}

The effect feedback includes four parts, which are to publish the learning results in the friends group of the WeChat, to evaluate the learning results mutually among the students, to improve the learning achievement and to evaluate the results by teachers [10].

15) Publishing learning outcomes on the friends circle

After the process of the deep learning, the students have mastered the knowledge needed to learn, completed the study and achieved some results according to the teachers' requirement. Each person publishes his own learning results in the friends group of the WeChat in the form of pictures or text, so that all the students can see them.

16) Mutual evaluate outcomes among students

After publishing the study results in the friends group of the WeChat, all the students can see each of the students' learning achievement and evaluate their learning achievements, So that they can further deepen the understanding and grasp of the course.

17) Improve learning achievement

Every student can combine the comments of the students and other students' learning achievement, and modify their own learning results to making the learning results to become more perfect and more in line with the teacher s' requirements.

18) The teachers' evaluation.

Teachers read over students' learning achievement in the friends group of the WeChat and evaluate students' deep learning results. At the same time, teachers can test the students' study by masssending the periodic tests on the WeChat public platform.

\section{Summary}

Deep learning is a kind of understanding learning which is based on the development of higher order thinking. It focuses on critical comprehension, emphasize the content integration and promote knowledge construction, and deliberately use the transfer etc. The WeChat is applied to the students in the process of deep learning in the paper. Combined with the distinctive features of the WeChat and several major advantages of the WeChat public platform, the curriculum design of deep learning is studied based on the WeChat under on the guiding principles of the teaching strategies of deep learning based the mobile Internet. At last the flow chart and the concrete implementation steps of the curriculum design are given and provide a very easy way to achieve the deep learning for university students in the mobile internet environment. With the further development of science and technology, extensive coverage of big data and cloud services, the improvement of the network software and hardware environment of colleges and universities, and the innovation consciousness of university teachers being increasing, the deep learning model based on mobile Internet will be greatly developed in the foreseeable future.

\section{Acknowledgment}

In this paper, the research was sponsored by the teaching research project of QiLu University of Technology (Project No. 2015024).

\section{References}

[1] Thomas F.2006. Disciplinary differences in faculty members'emphasis on deep approaches to learning[J].http://fsse.iub.edu/pdf/2006AIRFSSEDeepLearningFINAL.pdf.

[2] Ramsden, P. Context and strategy: situational influences of learning. In: R. R. Schmeck (Ed.) Learning Strategies and Learn-ing Styles. New York: Plenum Press. 1988: 159.

[3] Reid W. A., Duvall E. \& Evans P. Can we influence medical students.approaches to learning. Medical Teacher. 2005, Vol.27, No 5, 401 -407. 
[4] Floyd, K. S., Harrington, S. J. \& Santiago, J. The effect of engagement and perceived course value on deep and surface learning strategies. Informing Science: the International Journal of an Emerging Transdiscipline. 2009, Volume 12: 181 -190.

[5] Offir B, Lev Y. \& Bezalel R. et al. Surface and deep learning processesin distance education: synchronous versusasynchronous sys-tems. Computers \& Education, 2008 (51): 1172 -1183.

[6] Meyers, N. M., \& Nulty, D. D. How to use (five) curriculum design principles to align authentic learning environments, assess-ment, students.approaches to thinking and learning outcomes. Assessment and Evaluation in Higher Education, (2009). Vol. 34, No. 5,565 -577.

[7] Guixin Zhao Research on Teaching Strategies of Deep Learning based on the Mobile Internet ICEMCT 2015 P1448-1451.

[8] Lauren Cifiientes \& Omar Alvarez Xochihua. Learning in Web 2.0 Environments:Surface Learning and Chaos or Deep Learning and Self-Regulation? [J] .The Quarterly Review of Distance Education, 2011,1.

[9] M. Heijne-Penninga, J. B. Kuks,W. H. A. Hofman. Directing students to profound open-book test preparation: The relationship between deep learning and open-book test time. [J]. Medical teacher, 2011,33(1).

[10] Lynch Raymond; McNamara Patricia Mannix; Seery Niall. Promoting deep learning in a teacher education programme through self- and peer-assessment and feedback[J] European Journal of Teacher Education. 2012(2): 179-197.

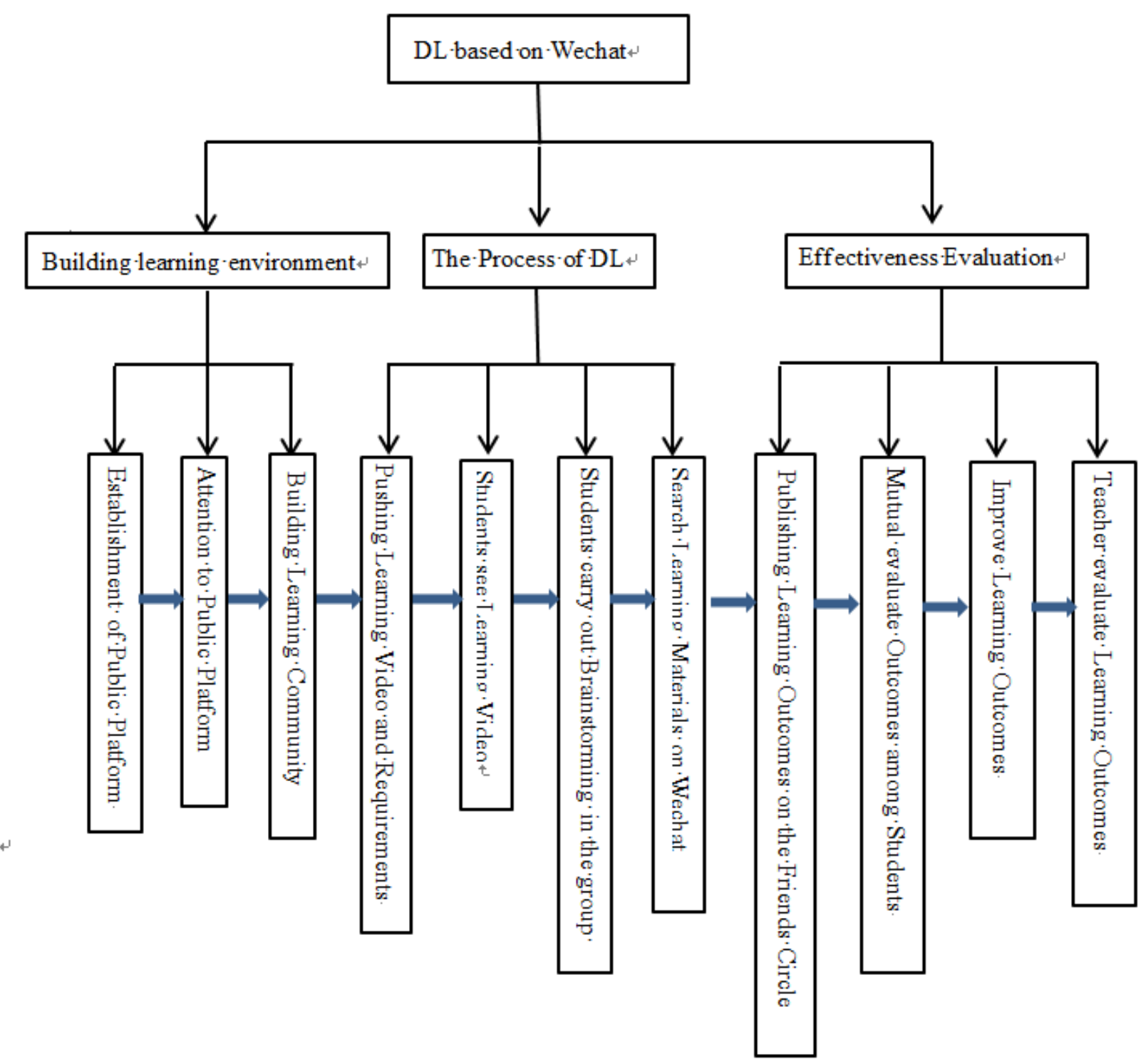

Figure 1. The flow chart and the concrete implementation steps of the curriculum design 